\title{
FRANCISCO DE ROJAS ZORRILLA, POETA DRAMÁTICO
}

Héctor Brioso Santos

Es Rojas Zorrilla uno de esos autores dramáticos áureos que sobreviven a caballo entre una discutible condición de segundones tras las tres grandes eminencias siempre citadas y la otra descripción típica como aspirantes a primeras figuras que "malograron" por algún concepto su posibilidad de entrar en tan selecto club de la historia literaria. Como prueba de que no es tan fácil ni tan hacedero desbrozar una producción dramática colectiva de miles de obras, pueden servir las XXII Jornadas de teatro clásico y, lógicamente también, este nuevo volumen de $\operatorname{actas}^{1}$ que puebla ahora, junto con algunos otros textos recientes, una cierta tierra de nadie bibliográfica en torno al dramaturgo toledano.

Algunos artículos o comunicaciones impresas en este libro tratan de indagar la extensión de lo cómico y en particular sus lindes no siempre del todo claras con el ámbito entremesil. Así, en especial, las secciones de Marta Villarino y Graciela Fiadino, "Nuevas formas de la comicidad en Abre el ojo" (pp. 89-101, particularmente en pp. 98-99); Enrico Di Pastena, "Sin honra no hay amistad y El desdén con el desdén. Aspectos del teatro cómico de Francisco de Rojas y Agustín Moreto" (pp. 103-119, especialmente pp. 112114); y Sofía Eiroa, "Las protagonistas femeninas de Rojas Zorrilla: Lo que son mujeres" (pp. 121-132, vid. sobre todo las pp. 126 y 130).

Quizá, aunque aparece concebido y organizado desde el criterio de análisis individualizado, singularizador, denostado por Vitse, pues se analiza colectivamente en él la obra de un dramaturgo con la saludable pretensión de rescatarlo de su relativo olvido (así lo subraya Pedraza en p. 8), es patente que extiende efectivamente un tanto los límites de lo estudiable en el terreno teatral que nos ocupa y, además, propende a alterar ciertas categorías ya contraproducentes, si no nocivas del todo. Incorpora, desde luego, nociones modernas acerca de la dramaturgia barroca (vid., por ejemplo, las alusiones de Cattaneo a las piezas "hacia arriba" y "hacia abajo" de Pedraza [p. 41], entre otras novedades).

Procediendo por orden, la sección de García de León Álvarez analiza y detalla las circunstancias físicas del corral de Almagro siguiendo la ya nutrida corriente de estudios de lo material teatral impulsada por John Varey, John J. Allen, Mercedes de los Reyes y Piedad Bolaños, entre otros (aunque no los cita a todos en su bibliografía, curiosamente, quizás por poner mucho énfasis en textos históricos más que de historia de la literatura).

\footnotetext{
${ }^{1}$ Francisco de Rojas Zorrilla, poeta dramático. Actas de las XXXII Jornadas de Teatro Clásico (Almagro, 13, 14 y 15 de julio de 1999), Felipe B. Pedraza Jiménez, Rafael González Cañal y Elena Marcelo, eds., Almagro, Universidad de Castilla-La Mancha, 2000, 421 págs.
} 
Sigue el texto de la comunicación de Cattaneo con un análisis que nos atañe directamente de los desenlaces trágicos y cómicos de Rojas, si bien no omite interesantes observaciones, entre otras cosas, acerca de los personajes femeninos rojanos (p. 41), una cuestión ya tradicional entre los críticos de este autor del XVII. Considera su producción dramática "no fácil e irregular" y señala que Rojas "desborda los esquemas" como experimentador que es (p. 42). Tales son los puntos de vista que conviene que un volumen de estas características difunda en nuestros días y, con pertinencia, esta autora aplica su interés a los llamativos finales del Rojas trágico y cómico. Interesan de esta sección algo irregular los juicios de conjunto sobre el debatido valor de Rojas (p. 51, por caso), aunque aparezcan en ellos pequeñas extrañezas como el "manierista del barroco" e importan matices como la afirmación de que Rojas permanece atento "a no superar la medida admisible" en sus excesos innovadores (ibid.).

Mi amigo Germán Vega García-Luengos nos brinda otro largo capítulo de su más que importante y prolongada labor de rescatador de las numerosísimas piezas de teatro clásico perdidas, extraviadas o disfrazadas en la debacle postbarroca y el muy destructivo siglo XIX. Le toca el turno esta vez a Mas vale maña que fuerza, obra a la que Vega GarcíaLuengos dedica aquí sus esfuerzos a varios niveles: imprenta, portadas, localización, resumen, análisis, escenificación, métrica, etc., con datos abundantes acerca de las tareas palaciegas de Rojas. El interesante estudio de Villarino-Fiadino ahonda en la "comicidad compleja" de nuestro autor (p. 99) justamente en la dirección que he consignado al comienzo de esta reseña. De este artículo sólo podría criticarse en buena ley su parquedad bibliográfica cuando se rozan y aun desbrozan claramente cuestiones teóricas tan sustanciosas como la relación entre la comedia y los llamados géneros menores (o breves) o la profundización rojana en la esfera de la risa más extrema.

El mismo terreno, en cuando a otra comedia, pisa Enrico Di Pastena en su comunicación, insistiendo en esa faceta de Rojas Zorrilla de la invasión por sus comedias de las fronteras entremesiles (pp. 112-114) y en lo que Arellano, con pleno acierto, llamó "la generalización del agente cómico en la comedia barroca", emparejando a Rojas con Moreto. Lleva, por último, este artículo una cumplidísima bibliografía. Eiroa estudia con entusiasmo a las protagonistas femeninas de Lo que son mujeres. Destaca facetas curiosas como la sensualidad de Rojas -con un ejemplo en el que coincido: esos baños voluptuosos de féminas medio desnudas que aparecen más de una vez en su teatro- $y$, de nuevo, lo entremesil y lo innovador en general de la comedia del toledano. Acaso puede criticarse que la autora no cite la edición más reciente y extensa de Entre bobos, aunque yo mismo ya he aludido alguna vez a los cortes leves pero poco afortunados sufridos por la edición de 1998 (Barcelona, Crítica) frente a la más completa -en algunos aspectos, que no en todos- de 1984 (Madrid, Taurus), siendo ambas de M. G. Profeti.

Me importa mucho detallar el contenido del artículo de Fernández Fernández, ya que trata la cuestión del figurón en Entre bobos, estudiada por la crítica en más de una ocasión. Si bien la definición del subgénero parece un poco vaga al principio (p. 133), mejora en seguida con observaciones muy atinadas acerca de la excesiva amplitud teórica de los (digámoslo así) conceptos-casillero de "capa y espada" y "enredo" (p. 134) e incluso con un golpe seco asestado a las más modernas interpretaciones del problema de la comedia clásica (ibid.). Acaso convendría que la autora recogiese en la p. 135 la ya mencionada 
teoría del agente cómico de Arellano, a cuyas tesis parece que se ponen serios reparos, junto con las de Vitse, en la página anterior. En cuanto al segundo rasgo anotado por la autora en esa página, éste también requeriría una nota o alusión a otra noción incorporada desde hace unos años a estos estudios como es la del galán suelto de F. Serralta, en un estudio que aparece sin embargo incluido en su bibliografía final. Interesan mucho las consideraciones acerca de la interacción entre figurón y gracioso (pp. 135-136), las precisiones que se aportan al primero (p. 136) y la conocida utilidad del marchamo "comedia de carácter" (p. 137) o lo pentagonal de la comedia de figurón (pp. 137-138), un extremo que he formulado en términos parecidos, aunque -lo confieso- menos precisos.

En particular, ha habido cierto debate en las últimas dos décadas sobre el subgénero de figurón, acerca de cuál es la primera pieza que lo incorpora y cuáles son las estructuras funcionales de estas comedias, materias todas para las que esta comunicación de Fernández Fernández nos brinda algunas soluciones que merecen ser tenidas en cuenta. Con todo, todavía me pregunto, a la vista de lo que escribe la autora (pp. 138 y 146), si realmente se casan don Luis y doña Alfonsa en el desenlace de la obra estudiada. Después es muy relevante la clasificación inédita de las piezas de figurón en tres tipos en los que, sin embargo, no queda clara la adscripción de Entre bobos, extremo que Fernández confirma con toda honestidad (p. 141), y es lógico dado que si hay un punto en el que la realidad de la comedia parezca totalmente inasible, es en el de la taxonomía, como todos sabemos. Subraya un ingrediente geográfico de la obra ya intuido por Profeti (p. 142), analiza el siempre estimulante problema del dinero en la comedia (p. 144) y atiende brevemente el problema del padre de la novia, entre otras cuestiones. En conjunto, sólo echo en falta en este artículo alguna interpretación del final de la pieza, asunto que todavía, como he anotado en varios artículos, me deja perplejo. Y el tono es, quizás, un poco pedagógico en una materia que ya ha alcanzado, a pesar de las limitaciones de la bibliografía existente, una altura bastante técnica (baste recordar las algo difíciles -por lo menos para mí- categorías de hiperfigurón, paleofigurón o semifigurón concebidas hace veinticinco años por JeanRaymond Lanot y Vitse).

Fernando Doménech estudia por extenso la comedia cortesana Los bandos de Verona, pieza con la que se inauguró el Coliseo del Buen Retiro. El autor nos ofrece una detallada descripción de las circunstancias de su estreno, de su argumento, las valoraciones de la crítica especializada moderna, sus fuentes y la interpretación barroca del sentido político simbólico de la pieza de Rojas (interesan especialmente las conjeturas de las pp. 158-164). Doménech corrobora finalmente la modesta calidad de la obra, pero subraya su importancia histórica, cosa que, en rigor, debe hacerse aún con muchas comedias.

María Teresa Julio analiza el antiguo y debatido problema del Rojas trágico, defendiéndolo de los abundantes ataques que se han hecho a sus tragedias. Aduce esta autora que el afán plenamente barroco de ofrecer abruptos contrastes de tono nos resulta más bien inasimilable a los lectores y espectadores modernos (p. 204; véanse también las importantes conjeturas de la p. 205). Y, como se sabe, la más o menos fácil adaptación a nuestros gustos no es el criterio ideal para juzgar el teatro clásico.

Marie-Françoise Déodat-Kessedjian aborda las obras escritas al alimón entre Rojas y Calderón, analizando en detalle los mecanismos internos que prestan cierta unidad a esas obras en equipo, a veces creadas por muchos ingenios. Juan José Pastor Comín y Alejandra 
Pacheco y Costa estudian las facetas musicales del teatro del toledano. Mientras Pastor resuelve las interacciones de la música y la creación literaria, Pacheco remite más en pormenor a un terreno que conoce perfectamente, como es la música, ofreciendo en un útil apéndice partituras y detalles técnicos que raramente encontramos en los estudios críticos de nuestro ámbito y de las que haré partícipes a algunos de mis alumnos, interesados en ese particular, que merece consideración aparte.

Las secciones comparatistas de Antonio Ballesteros González y Christophe Couderc estudian respectivamente el influjo de Rojas en el inglés William Davenant, comediógrafo de la Restauración, y en el teatro francés del XVII. Siguiendo con los estudios de recepción literaria y teatral, Emilio Palacios Fernández, especialista en el teatro dieciochesco, analiza la pervivencia de Rojas en el XVIII, completando los conocidos estudios de René Andioc y Mireille Coulon. Como es lógico, no omite referirse a las críticas lanzadas por los neoclásicos a la obra de nuestro dramaturgo. El capítulo de María Elena Arenas Cruz ahonda más en la cuestión con una visión detenida de las representaciones de obras de Rojas en el XVIII, revisadas a través del testimonio del Memorial literario, ofreciéndonos un estudio de la cartelera teatral de la época. Por último, en un breve estudio, Andrés Peláez Martín se ocupa de sopesar la presencia de Rojas en la escena desde mediados del XVIII hasta nuestros días. Su conclusión era predecible: injusta pero efectivamente, desde hace mucho tiempo, la única obra conocida de nuestro dramaturgo para el público es la encantadora y magnífica Entre bobos anda el juego, pieza capaz de sostenerse en las condiciones dramáticas más adversas y de resistir las mutilaciones más arbitrarias (hace poco un joven director me sugería la posibilidad -jotra vez!- de modernizar la obra...).

Precisamente, en las dos crónicas resumidas de los coloquios del congreso que siguen se ponen de manifiesto (y se atajan oportunamente por los estudiosos presentes) algunos de los prejuicios tan frecuentemente visibles y tan perniciosos en las lecturas o la recepción espectacular del teatro barroco hoy día: especialmente la (in)comprensión anacrónica desde una teatralidad moderna -F. Pedraza se vio obligado a aclarar que Rojas "no es Chejov" (p. 410)- y el a medias cierto y a medias falaz argumento contrario, tantas veces esgrimido en estos días, de que el teatro no es sólo para estudiosos, que en muchos casos es lanzado al debate por directores y actores con una menos que somera formación histórica. El caso de Cristina Marcos, actriz de la Compañía Nacional de Teatro Clásico y filóloga, presente en estas sesiones, sirve de evidente modelo de conducta práctica en el que muchas gentes de teatro deseosas de modernizar a contrapelo textos áureos podrían inspirarse con provecho para todos, eruditos y público medio.

Hay en este libro algunos leves descuidos formales: algunos despistes del artículo de Cattaneo perturban un poco su lectura (falta un "el" en p. 43, por ejemplo); falta una cursiva de un título en p. 112 y hay un uso algo anómalo de los paréntesis en la p. 124. Quizá la práctica general en este libro de repetir literalmente los nombres de los autores con más de una entrada en las bibliografías no parece del todo acertada (pp. 52 o 85-86, por ejemplo), y más aun cuando se trata de la misma obra, vista como introducción y como edición (las entradas de Profeti en pp. 52 y 53). Se trata de cuestiones que suelen simplificarse por mor de la brevedad y en beneficio del lector. Me extraña también el pie de grabado en inglés de la p. 321, acaso una exigencia formal de la biblioteca británica que ha permitido su reproducción. Hay algunas inconsistencias sintácticas y de puntuación en la 
p. 323, por ejemplo, y el sentido de la palabra "lectorado" de la p. 327 me sorprende un tanto.

En suma, desde ahora contamos con un importante volumen dedicado a la producción dramática de Rojas Zorrilla que complementa la relevante labor de indagación sobre ese dramaturgo iniciada en la edición de Obligados y ofendidos (Madrid, RESADFundamentos, 2000). Es de señalar también el interés de las publicaciones de la Universidad de Castilla-La Mancha, que, junto con el muy vasto catálogo de Reichenberger y los esfuerzos notables del GRISO, están ampliando cada vez más los materiales de calidad disponibles sobre el teatro áureo, tanto en el aspecto teórico como en el de los textos. 